\title{
Nurses' Leadership Style in Tertiary Care Hospitals
}

\author{
Article by Nauman Q. Godfrey \\ MSN-Texila American University, M.Sc Psychology (Clinical), Pakistan \\ E-mail: enqamar@hotmail.com
}

\begin{abstract}
The present study showcases the leadership style of head nurses of Tertiary Care Hospitals in Pakistan (Lahore). Purpose is to see that what type of leadership style is mostly practiced / adapted. For data collection, quantitative methods are employed that includes a scale LPS (least preferred coworker scale) and checklists to assess head nurses that either they are relationship motivated or task motivated. Two lists were made named as A and B for getting data about autocratic and democratic style respectively. Total sample from the populating of nurses and head nurses was $65(n=65)$ among which 18 are head nurses and 47 are charge nurses. From 18 head nurses 3 are task motivated (17\% of total sample), 13 are relationship motivated (72\% of total sample) and 2 are mixed of mixed leadership style $(11.1 \%$ of total sample). The checklists revealed similar findings that remained consistent further strengthening the results. It was concluded that Democratic Leadership Style is most rampant in Tertiary Care Hospitals. The head nurses are very encouraging and they appreciate every creative idea from their colleagues. They promote collaborative work. They support every initiative taken for the betterment. The head nurses of Tertiary Care Hospitals share the decision making and problem-solving responsibilities with their colleagues. Charge nurses develop a greater sense of selfesteem due to importance given to their ideas and contribution.
\end{abstract}

Keywords: Nurse. Tertiary Care. Hospitals. Leadership. Styles.

\section{Introduction}

Leadership in nursing is an art, a science, an ambition. It is based on personal qualities, on strategic skills and also on the will to change the course and outcomes. It can occur in all clinical positions performed by a nurse. Nurses are the backbone of any healthcare system. This is the utmost reality and is the most significant statement that is heard almost all the time when talking about nurses and nursing profession. Leadership is generally associated with personal qualities. However, it is increasingly mentioned that it is also a professional competence. Therefore, it makes it mandatory to analyze the strengths and weaknesses of what is important to us and nursing profession. The present study is the leadership style of head nurses of Tertiary Care Hospitals in Pakistan (Lahore). Purpose is to see that what type of leadership style is mostly practiced / adapted.

For a national impact, it is necessary to invest places of power or influence, both within the profession and outside. In France, the order of nurses is weak and marginalized. Trade unions are strong, but they are opposed to the evolution of the profession; they are responsible for the status quo that prevails within the nursing discipline. Some nursing associations are present in the field, but lack visibility and dynamism. In Canada, within the nursing profession, clinical leadership is increasingly valued. It involves not only technical skills and a developed ethical sense, but also an ability to innovate and change care practices. This innovative leadership can coexist with multidisciplinary. In this way, the leader nurse conceives his / her role as a caregiver beyond care and dares to propose changes in practice, speak out, advocate for the interests of patients, take his place in the interdisciplinary team and define himself as an expert in care. Nursing leadership can be measured in terms of its area of influence from expert practitioners and reflective practitioners to the opinion leader and transformation agent of society. 
DOI: $10.21522 /$ TIJNR.2015.03.02.Art003

ISSN: $2520-3126$

\section{Methods}

Cross-sectional research design is used to carry out the research and it was hypothesized that nurses have the democratic style of leadership. The population included the head nurses and charge nurses of the tertiary care hospitals of Lahore, Pakistan and a sample of 65 nurses is selected for this study. Out of which 18 are head nurses and rest of the sample of 47 is collected systematically from sub-ordinates of each head nurse to get a fully represented sample. The research instruments include meticulously formulated checklist and least preferred co-worker scale. Which is interpreted as, if score is 73 or above, the person is a "relationship-motivated" leader; if score is 64 and below, the person is a "task-motivated" leader. If score is between 65 and 72, it's a mixture of the two.

\section{Results}

Scores of head nurses on least preferred coworker scale

\begin{tabular}{|c|c|c|c|c|c|c|c|c|c|c|c|c|c|c|c|c|c|c|}
\hline Sr. \# & 1 & 2 & 3 & 4 & 5 & 6 & 7 & 8 & 9 & 10 & $\begin{array}{l}1 \\
1\end{array}$ & $\begin{array}{l}1 \\
2\end{array}$ & 13 & $\begin{array}{l}1 \\
4\end{array}$ & $\begin{array}{l}1 \\
5\end{array}$ & 1 & $\begin{array}{l}1 \\
7\end{array}$ & $\begin{array}{l}1 \\
8\end{array}$ \\
\hline LPC & 4 & 9 & 8 & 10 & 6 & 11 & 9 & 10 & 9 & 10 & 7 & 7 & 12 & 9 & 8 & 8 & 7 & 6 \\
\hline $\begin{array}{l}\text { Scor } \\
\mathrm{e}\end{array}$ & 0 & 9 & 1 & 0 & 9 & 7 & 0 & 0 & 0 & 3 & 5 & 1 & 7 & 0 & 4 & 7 & 2 & 3 \\
\hline
\end{tabular}

Possible highest score of each individual $=144$ Possible lowest score each individual $=18$

Score of 73 or above $=$ Relationship-motivated $\quad$ Score of 64 and below $=$ Task-motivated

Score between 65 and $72=$ Mix of both

Total score $=1558$

Mean $=1558 / 18$

$=86.56$

\section{Scores of head nurses on Least Preferred Coworker Scale}

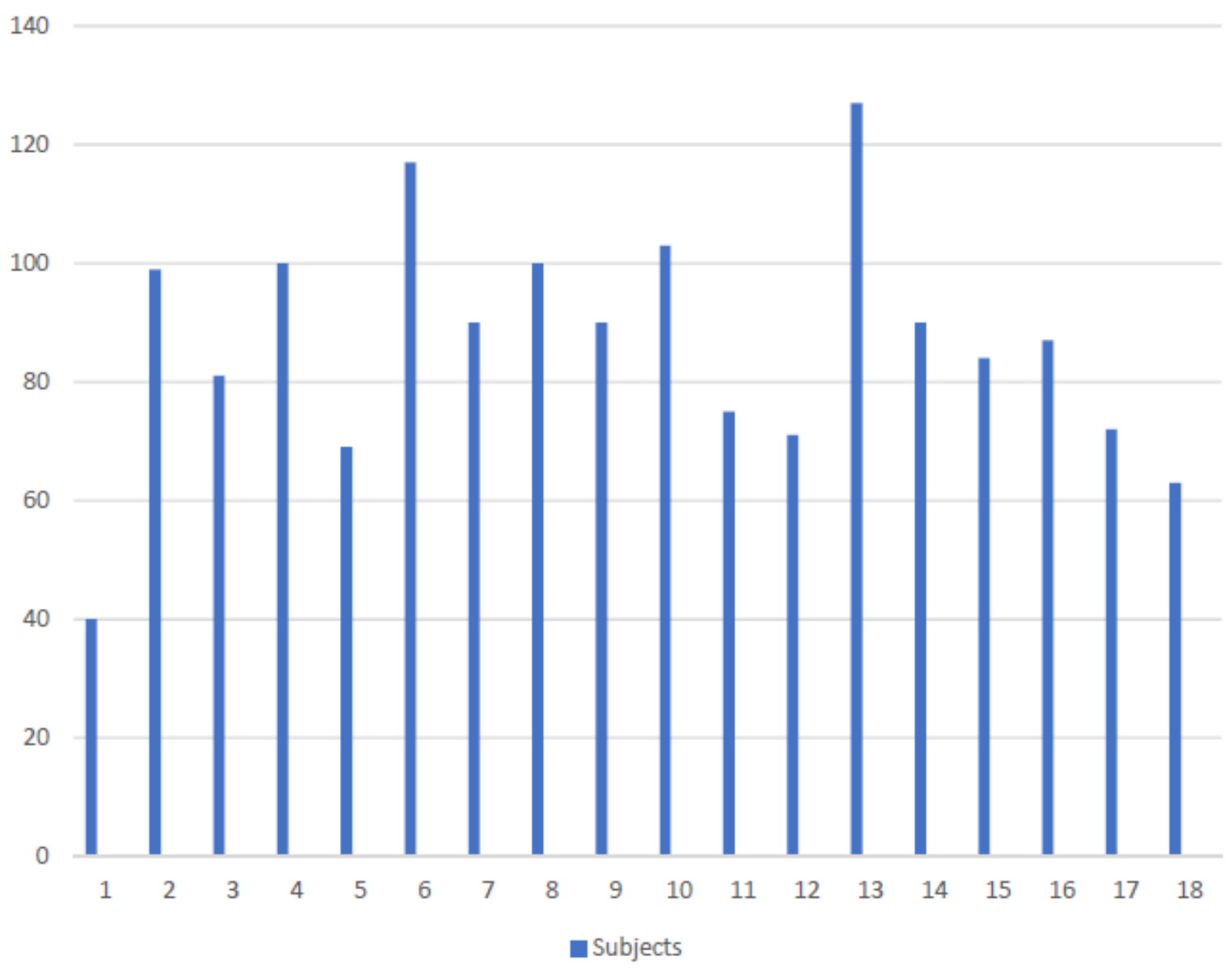


The scores of the representative sample of charge nurses on the check list "A" \& " $\mathrm{B}$ " is as follows.

\begin{tabular}{|l|l|l|l|l|l|l|l|l|l|l|l|l|l|l|l|l|l|l|l|l|l|l|}
\hline Sr. \# & 1 & 2 & 3 & 4 & 5 & 6 & 7 & 8 & 9 & 10 & 11 & 12 & 13 & 14 & 15 & 16 & 17 & 18 & 19 & 20 & 21 & 22 \\
\hline List A & 6 & 7 & 8 & 4 & 2 & 2 & 7 & 7 & 7 & 8 & 5 & 7 & 4 & 9 & 6 & 5 & 9 & 9 & 6 & 5 & 6 & 4 \\
\hline List B & 7 & 8 & 4 & 7 & 10 & 10 & 4 & 9 & 9 & 10 & 7 & 7 & 7 & 8 & 10 & 1 & 4 & 5 & 9 & 9 & 10 & 3 \\
\hline
\end{tabular}

\begin{tabular}{|l|l|l|l|l|l|l|l|l|l|l|l|l|l|l|l|l|l|l|l|l|l|l|l|}
\hline 23 & 24 & 25 & 26 & 27 & 28 & 29 & 30 & 31 & 32 & 33 & 34 & 35 & 36 & 37 & 38 & 39 & 40 & 41 & 42 & 43 & 44 & 45 & 46 \\
\hline 7 & 4 & 3 & 9 & 5 & 6 & 2 & 2 & 7 & 5 & 3 & 3 & 7 & 5 & 7 & 5 & 2 & 4 & 2 & 5 & 4 & 5 & 6 & 1 \\
\hline 8 & 10 & 10 & 10 & 4 & 6 & 8 & 9 & 9 & 5 & 7 & 10 & 10 & 6 & 9 & 1 & 10 & 7 & 6 & 5 & 10 & 5 & 10 & 10 \\
\hline
\end{tabular}

Possible highest score on checklist $=10$

High score on checklist A = Autocratic

Equal score on either checklist $=$ Mix of both

Total score on checklist $\mathrm{A}=257$

Mean score on checklist $A=257 / 47=5.4$
Possible lowest score on checklist $=0$

High score on checklist $\mathrm{B}=$ Democratic

Total score on checklist $\mathrm{B}=276$

Mean score on checklist $B=276 / 47=5.8$

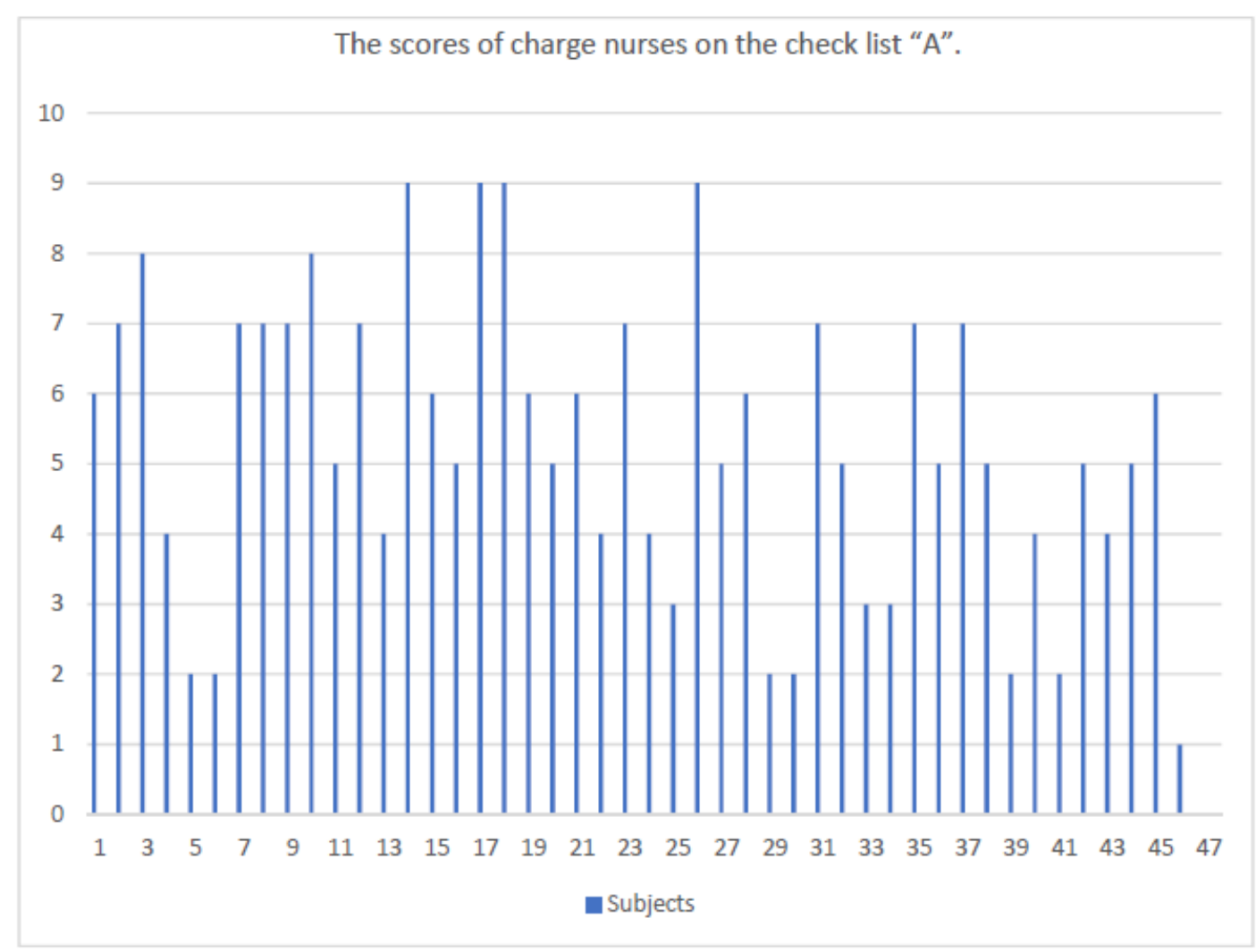


DOI: $10.21522 /$ TIJNR.2015.03.02.Art003

ISSN: $2520-3126$

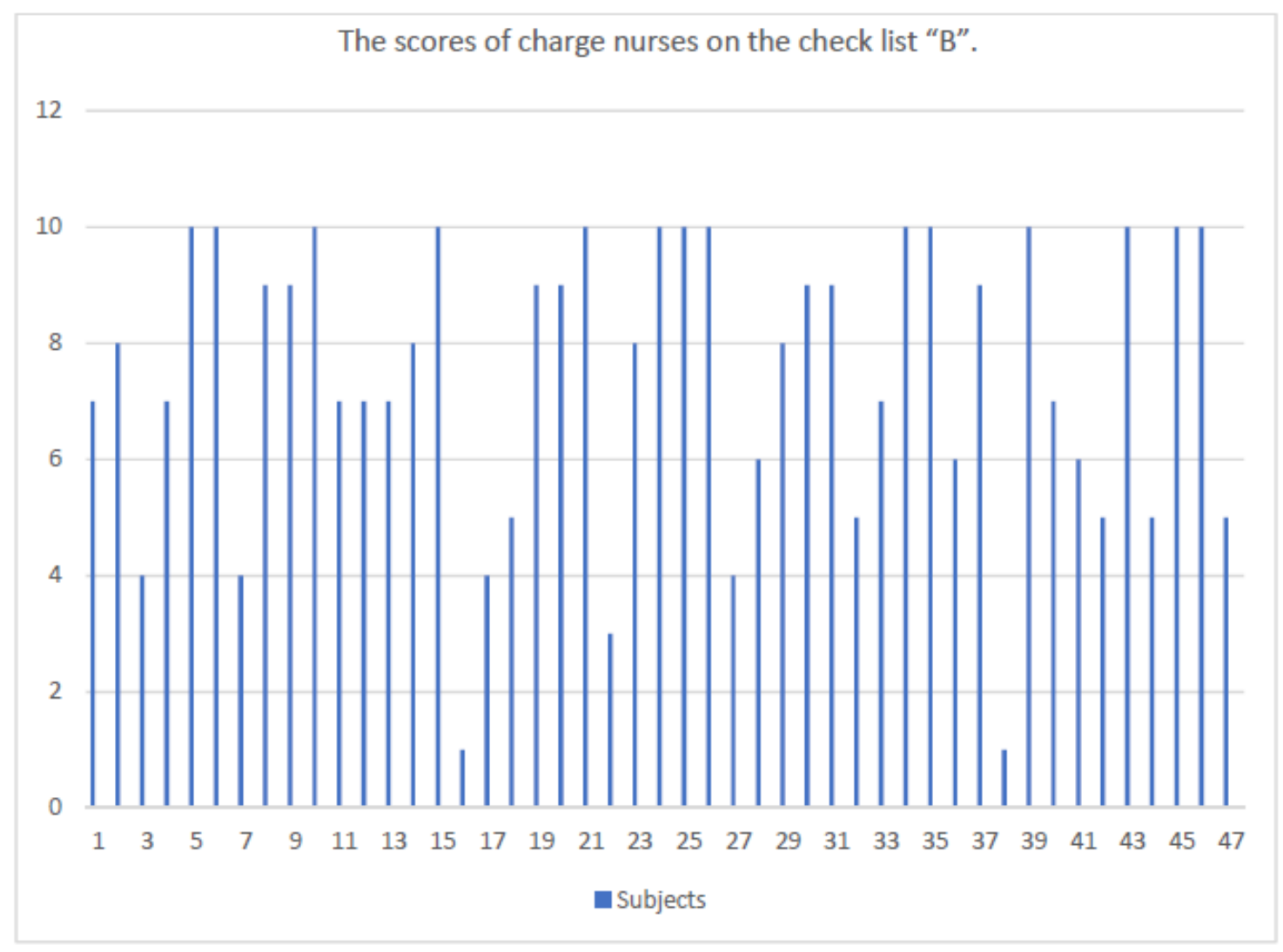

\section{Discussion}

The present study is about the leadership styles of head nurses in tertiary care hospitals. Carrying out this study \& by using observation skills, scale \& checklists it was revealed by results that Democratic leadership style is most pertinent to all head nurses in tertiary care hospitals. Democratic leadership style is the most effective style, group members are encouraged to share ideas and opinions, members of the group feel more engaged in the process. Creativity is encouraged and rewarded. Democratic leadership style leads to higher productivity. In democratic leadership staff will readily accept policies and decision that were conveyed by the head nurses.

When nurses are familiar with leadership theories, they can select and adapt the most appropriate proposals to deal with different situations. As a model, the Nursing leader can reduce the autocratic atmosphere and therefore, some conflicts of functions. Leaders do things right, accept the challenge of change, focus on goals and have a marked time in the future. They ask why and use strategies based on trajectories towards human potential. On the other hand, managers do things right, opt for continuity, and focus on current structures and procedures. They ask who, what, when, where and how because they use programs to reach the destination and evaluate human performance.

The different theories on leadership. The theory of the great man: this theory holds that a few people are born with the characteristics necessary to be great. They are very mature and simultaneously demonstrate an instrumental and support leadership behavior. Instrumental activities include the planning, organization and control of the activities of subordinates to achieve the objectives of the organization. Support leadership is socially oriented and allows subordinates to participate and consult on decisions that affect them. People who use both leadership, instrumental and support behaviors are considered "great men" and are supposed to be effective leaders in any situation. Many consider this theory unattractive since it states that leaders are born and are not made.

Theory of the Charism: People can be leaders because they are charismatic, which is a quality by which, with their presence alone. They make others feel better. The charismatic leader inspires by gaining the emotional commitment of the followers awakens strong feelings of loyalty and enthusiasm. Through this type of leadership, obstacles can be overcome that were believed insurmountable, however, because the charisma is so vague, some can perceive it while others do not. Charismatic 
leaders believe strongly in their opinions, have great self-confidence and the need for power. Followers of charismatic leaders trust the leader's opinions, have similar judgments, show affection, obedience and unquestioning acceptance towards the leader and are emotionally involved, so they feel they can contribute to the mission. The problem lies as we have mentioned earlier in that not all people perceive the charismatic leader in the same way.

Trait Theory: Until the mid-1940s, feature theory was the basis for most leadership research. Early studies in this area maintained that traits were hereditary, but later theories indicated that traits could be acquired through learning and experience. Researchers identified the following leadership traits: energy, strength, enthusiasm, ambition, aggressiveness, self-confidence, self-confidence, sympathy, affection, honesty, fairness, loyalty, security, technical mastery, and instructional ability. It is from the combination of these characteristics that arise the different types of leadership more known.

Autocratic: the autocratic leader makes the decisions alone by relying on the authority that provides his position. The management is exercised by issuing orders and waiting for compliance. They tend to be directive, critical and punitive. They are attributed a situation higher than the members of the group, which diminishes open communications and confidence. They also retain responsibility for all goals and decision making. Tend to a good performance, quantitatively and qualitatively, but under autonomy creativity or self-motivation; this is usually appropriate in emergency situations, when the leader knows what to do, but does not encourage people. The motivation is done by sanction / reward.

Participatory: The boss proposes different alternatives to the group that asks for an opinion, although the boss is ultimately the one who decides.

Democratic: Democratic leaders maintain less control, rather than asking for results, ask questions and suggestions, and involve the group in planning, problem-solving, and decision-making. Participation has to increase motivation and creativity. They work when people have knowledge and skills and work well as a team. It can be uncomfortable. It is often less effective than autocratic control.

Laissez faire or liberal: it consists of a very permissive, non-directive, passive and inactive type of leader. The person in charge has a role of mere facilitator of the team work, giving him information, but it is the subordinates who make the decisions. Group members can work independently and possibly with misunderstandings because there is no planning or coordination and little cooperation. Chaos may occur unless an informal leader emerges. This style can work with very mature and self-employed workers, but it is more likely to be ineffective and unproductive.

\section{Conclusion}

The mean score of 86.56 on LPC Scale reveals that head nurse's relationship oriented. The checklists revealed similar findings that remained consistent further strengthening the results. It was concluded that Democratic Leadership Style is most rampant in Tertiary Care Hospitals. The head nurses are very encouraging and they appreciate every creative idea from their colleagues. They promote collaborative work. They support every initiative taken for the betterment. The head nurses of Tertiary Care Hospitals share the decision making and problem-solving responsibilities with their colleagues. Charge nurses develop a greater sense of self-esteem due to importance given to their ideas and contribution. Leadership styles towards staff nurses show significant effects of productivity efficiency and reflects positive or negative patient outcome.

Leadership characteristics. Vision. An idea or perspective of the future and potential opportunities. From it results the purpose or the main reason of being of the organization (the mission), and the goals that establish its general direction. The vision must influence everyone who works in the organization. Vision means long-term thinking; look beyond the present day or the next few months, beyond the horizon. It means considering how other factors in the organization's environment can influence the organization and its future. Influence. The ability to contribute to change the thinking and behavior of others or create new policies or legal texts that will be important for the future. It may also mean (for nurse leaders) to influence the general managers of health services and make contributions to overall management decisions and policies. Motivation. Demonstrate commitment and energy to work for the realization of the vision and the achievement of the goals. Generate in others an enthusiasm, commitment and sense of purpose before shared goals, and a motivation to achieve them. Trust. Build trust in others by clearly outlining strategies for vision, and be sure that those strategies are appropriate. 
DOI: $10.21522 /$ TIJNR.2015.03.02.Art003

ISSN: $2520-3126$

Leaders have the ability to draw people toward shared goals. They have confidence in themselves and in what they are doing. Political competence. Understand and accept different goals and behaviors of different stakeholder groups. Understand the connections between the different events and influences that have an impact on the organization. Plan strategies to respond effectively to these influences. Select and use the best combination of talents in your team, to help achieve different goals. Review and change. "Renewal" means that processes and structures of the organization are not always accepted as they exist, rather they are reviewed in response to an assessment of results or changing needs. Turn problems into opportunities.

\section{References}

[1]. Careers, Finance and Investing. Money-zine.com. Retrieved March 16, 2012.

[2]. Coombs, M. \& Dilon, A. (2002). Crossing boundaries, re-defining care: the role of the critical care outreach team. Journal of Clinical Nursing, 11(3), 387-393.

[3]. Ericksson, J. \& Ditommassi, M. (2005). The clinical Nurse Leader: New in Name Only. J Nurs Educ, 44(3): 99-100.

[4]. Erben and Guneser, Gul and Ayse (November 2008). "The Relationship Between Paternalistic

[5]. Foster, D.E. (2002). "A Method of Comparing Follower Satisfaction with the Authoritarian, Democratic, and Laissez-faire Styles of Leadership." Communication Teacher 16 (2): 4-6.

[6]. Johnson, C. E.; Hackman, M. Z. (2003). Leadership, a communication perspective (4 Ed.). Waveland Press. p. 38. ISBN 9781577662846.

[7]. Leadership and Organizational Commitment: Investigating the Role of Climate regarding ethics". Journal of Business Ethics 82 (4): 955-968. Retrieved 12/1/2012.

[8]. Leadership Styles - Autocratic, Laissez Faire, Participative and Bureaucratic". Management Study Guide. Retrieved 19 March 2012.

[9]. Martindale, N (2011). "Leadership Styles: How to handle the different personas". Strategic Communication Management 15 (8): 32-35.

[10]. McCallin, A. (2003). Interdisciplinary team leadership: A revisionist approach for an old problem. Journal of Nursing Management. 11, 364-370.

[11]. McCallin, A. (1999). Pluralistic dialogue: a grounded theory of interdisciplinary practice. The American Journal of Rehabilitation Counselling, 5(2), 78-85.

[12]. Nelson, E., Batalden, PB, Huber, TP., Mohr, JJ., Godfrey, MM., \& Headrick, LA. (2002). Microsystems in health care, Part I: Learning from higher performance frontline clinical units. J Qual Improv. 2002; 28(9): 472493.

[13]. Porter-O'Grady, T. (2000). Vision for the 21st century: new horizons, new health care. Nursing Administration Quarterly, 25(1), 30-38.

[14]. Rowold, Jens; Schlotz, Wolff (Spring 2009). "Transformational and Transactional Leadership and Followers' Chronic Stress". Leadership Review (Kravis Leadership Institute) 9: 35-48.

[15]. Schultz \& Schultz, Duane (2010). Psychology and work today. New York: Prentice Hall. pp. 201-202. ISBN 0-205-68358-4.

[16]. Styles of Leadership". Assortment. Retrieved March 16, 2012.

[17]. Sabo, JA. Combere, PC. Rusch, A., \& Wilson, W. (2005). Developing an Outcome-based Multidisciplinary Care Planning Tool: Process and Outcome. J Nurs Care Qual 20(2). 145-155.

[18]. Scott, L. (2005). Shared governance and shared leadership: meeting the challenges of implementation. Journal of Nursing Management, 13, 4-12.

[19]. Tornabeni, J., Stanhope, M. \& Wiggins, M. (2006). Clinical Nurse Leader Evolution of a revolution. The CNL Vision. JONA. 36(3). 103- 108.

[20]. Woods, A.P. (2010). "Democratic leadership: drawing distinctions with distributed leadership". International Journal of Leadership in Education 7 (1): 3-36.

[21]. Wilson, N.L. \& Gleason, M. (2001). Team roles and leadership. In Interdisciplinary team leadership: A revisionist approach for an old problem. McCallin. 